\title{
Expansion of Natural Dye Colour Gamut for Use by the Local Textile and Craft Industry
}

\author{
Walter Chipambwa ${ }^{1 *}$ and Jacob A Nyathi ${ }^{2}$ \\ ${ }^{1}$ Chinhoyi University of Technology, Chinhoyi, Zimbabwe \\ ${ }^{2}$ National University of Science and Technology, Bulawayo, Zimbabwe
}

Submission: September 26, 2017; Published: November 10, 2017

"Corresponding author: Walter Chipambwa, Chinhoyi University of Technology, Zimbabwe, Email: wchipambwa@cut.ac.zw

\begin{abstract}
Natural dyes have been used since long back in various areas such as textiles, craftwork, food colouring and also as medicine. This work was based on expansion of the colour shade that can be obtained from natural dyes for use by the small scale users. The natural dye was extracted from three naturally available plants locally in Zimbabwe using the cold extraction under gravity method. An alcohol was used to extract the dye using a vacuum pump and left to dry. The extracted dye was then used to dye fabric strips using different metals as mordants. From the colour charts generated from the various dyeings it was shown that the shades can be extended for certain plants and in some cases they are not easy to expand. Application of the metal mordants at different concentrations was also found to have an effect on the hue of the dyed fabric strips. The results show that the natural dye from the Mukwa (Pterocarpus anglonesis) gave a wider range of shades as compared to the other two dyes.
\end{abstract}

Keywords: Natural Dye; Colour; Mordant; Synthetic; Textile

\section{Introduction}

Humans have used natural dyes for colouration thousands of years before 10,000 BC with the oldest examples being prehistoric cave paintings, which show the already-sophisticated use of carefully-graded colours [1]. All textile materials be they natural or synthetic they are dyed creating a better aesthetic value and in line with customer expectations. Anciently, the dyeing process to textile materials and other craft products was accomplished through use of colours of natural source, up until synthetic colours or dyes were invented and commercialized. The sources of these natural colours or dyes include insects, plan leaves, fruits and roots. But nowadays most of the colours used in commercial textile dyeing are synthetic colours [2]. Historically colours commonly derived from plants included yellows, largely extracted from weld (Reseda Luteola), but also found in other plant species like quercitin and persian berries. Madder (Rubia tinctorum) is known to be the most important source of the red dye alizarin, though some other reds were also extracted from insects like cochineal and kermes [2]. The colour black was obtained mainly from logwood, although it could also be made from mixing dyes of other colours [3].

As of late there has been a growth and interest in the use of natural dyes in textile colouration. This is to some extent, attributed to the strict environmental standards enacted by many countries in response to the toxic and allergic reactions associated with synthetic dyes [4]. Natural dyes are more environmentally friendly than synthetic dyes and can exhibit better biodegradability and generally have a higher compatibility with the environment [5-6]. Currently the global demand for natural dyes world over is about 10,000 tonnes, which is equivalent to $1 \%$ of the world synthetic dyes consumption in the whole world [7].

Within the food industry natural dyes can also be used as colourants though they have some disadvantages compared with synthetic colourants as they are more expensive and less stable, but with the advent of a well-informed consumer who is very particular about their health natural colourants or pigments are gaining attention as they are considered harmless or even healthy [8]. In some countries like the United States and the European Union they have restricted the use of synthetic colourants as food additives thereby increasing the uptake of natural colourants in the food industry as consumers require foods to be as natural as possible [9].

In their research in rural part of south eastern Zimbabwe [10] identified the use of birchemia discolor in colouring the art products done by the rural folk. The bark of birchemia discolor may be collected and also branches or even roots, and then boiled in water to produce dye used to colour the craft products [10]. The fibre to be dyed is then soaked in this solution, until 
the desired purple colour is achieved, and then hung in open air to dry. [11] states that due to the economic hardships that have befallen most families in rural Zimbabwe accompanied by severe droughts, families have had to look for alternative sources of income in order for them to survive such as harvesting, processing, and sale of craft products. The increase in tourism activities in post independent Zimbabwe has also contributed to growth in demand for curios and craft items, including those made from bark [12].

Natural dyes are less toxic, less polluting, less hazardous as compared to synthetics, non-carcinogenic and non-poisonous. They also do produce harmonizing colours which are gentle, soft, subtle and create a restful effect. Above all they are environmentally friendly and promote the issue of sustainable in dyeing principles. Extensive use of natural dyes as sources of colourants requires one to do multiple dyeing cycles in order to produce deeper shades and also the addition of a suitable mordant for the achievement of different colour depths required. The problem of a limited number of shades has affected the appreciation of natural dyes by many and also their unavailability for large scale processing. On the crafts produced the local Zimbabwean communities there is evidence of use of the natural colours [10]. These brilliant decorations provide a unique selling point as it is a combination of mastering the colours and the art of decorations which can make one sell their products for a good return. These communities depend on the income they get from the sale of their artifacts therefore empowering them with the knowledge on how to improve their colour ranges is beneficial. Providing an extension of the shade gamut obtained from various natural colours extracted locally in Zimbabwe is important as it gives the local crafts people a wider selection of use for their dyeing activities. Colour on its own is a very important part as it affects the aesthetic appeal of any textile product. The ability to provide a wide range of colours within the natural colours is therefore important as it brings more variety in design.

In areas where synthetic dyes, and other processing chemicals or additives are imported resulting in higher costs to dye, natural dyes can offer an attractive alternative [13]. Zimbabwe has abundant natural forest resources which can be a source of quite a number of these natural dyes. As of late there has been more push worldwide to promote sustainable practices in the way live. Within the field of textile dyeing one such method is through use of natural colouring matter as it is not harmful to the environment as compared to synthetics. This study therefore seeks to improve on some of the shortcomings which are prevalent with use of natural dyes as a colouring matter, with an effort of empowering the local craft industry who earn lives through this trade. Natural dyes have been used in different areas for a long time though on a rather small scale therefore production of a colour chart and recipe guides to achieve different shades can be also of importance to various industries. Commercialization of the locally found natural dyes in Zimbabwe is very possible and can be improved if the shade ranges are also standardised.

\section{Overview of natural dyes}

The colours obtained from natural plants are always a varying parameter as this is determined by the impurities peculiar to that plant material used. This is one of the reasons they have not been popular by dyers at large scale who would want to standardise their colours. This is what made these natural dyes lose out on the market to the synthetic dyes though they are appealing to today's craftsmen as they seek to capitalize on this uniqueness in natural dyes. One of the most successful projects on natural dyes is the Dogal Boya Arastirma veGelistirme Projesi (DOBAG) of Anatolia in Turkey. In this project natural dyes have been used to print fine Turkish carpet prints that are highly valued and attractive [14]. In India there is also a natural dye project Aranya supported by Tata Tea which helps in employment of the physically handicapped and also family members of the employees of Tata Tea [14]. Most natural dyes give a shade of brown or beige when used as a fabric dye. Others produce strong brilliant colours but they have poor fastness properties for both light and washing [15].

\section{Other uses of natural dyes and their sources}

Table 1: Local sources of natural dyes.

\begin{tabular}{|c|c|c|c|c|c|}
\hline Botanical name & Common name & Shona name & Ndebele name & Part used & Colour/s \\
\hline Adonisia digitate & baobab & muuyu & umkhomo & Fruit & brown \\
\hline Aloe & aloe & gavakava & ichena & leaves, roots & yellow, beige \\
\hline Bichemia discolor & bird plum & munyii & umnyi & Roots & pink \\
\hline Brachystegia spiciforms & msasa & musasa & igonde & ark & red \\
\hline Euclea divinorum & diamond leaved & muchekisani & umtshekisani & root, bark & brown \\
\hline Julbernardia glibiflora & munondo & munondo & umshonkwe & Bark & red brown \\
\hline Lannea discolor & live long & mugan'acha & isigangatsha & lower bark & red, brown \\
\hline Ozora insignis & raising bush & murunganyama & isafice & Roots & rink \\
\hline Parinari curatellifolia & mobola plum & muchakata & umkhuna & bark, roots & brown \\
\hline
\end{tabular}




\section{Current Trends in Fashion Technology \& Textile Engineering}

\begin{tabular}{|c|c|c|c|c|c|}
\hline Pilistigma thonningii & monkeybread & mujekenje & ihabahaba & Bark & beige-brown \\
\hline Pterocarpus anglonesis & mukwa & mubvamaropa & umvagazi & Bark & red \\
\hline Sclerocarya birrea & marula & mupfura & umgano & fruit, bark & brown \\
\hline Vitax payos & chocolate berry & mutsubvu & umtshonkelwa & bark & purple \\
\hline
\end{tabular}

Natural dyes have been used for many centuries as hair and face colourants. Thousands of years ago it was common practice for Indians to tint their faces yellow with saffron and to dye their feet red with henna. In similar times Chinese women used vegetable extracts to dye their feet, cheeks and tips of their tongues. Several dye yielding plants can also contain substances with pharmaceutical properties. Modified aniline can be used as an important drug and as well as a dye Table 1. Traditionally the Msasa (Brachystegia spiciformis) tree which produces a red dye has been used to cure some ailments like dysentery and malaria [16]. Fruits from the Marula (Sclerocarya birrea) produce a natural red dye and they can also be used as food source as well as brewing of beer known as mukumbi locally in Zimbabwe. Natural dyes can also be used in the food industry and the medicine industry $[1,17]$. Within the food industry their application faces challenges as they exhibit chemical instability, poor tinctorial power and limited number of shades available for example beetroot can produce a deep red colour but the extracted pigment is unstable [17].

\section{Mordanting process}

A mordant is a substance which serves to fix the colour on the textile substrate. From a single coloured dyestuff various shades can be obtained by simply varying the mordant used [18]. Therefore, the addition of a mordant can change the $\mathrm{pH}$ of the dyebath and hence the colour and thus help in the absorption of the colour to the fabric. Mordants are generally composed of metallic oxides or earth oxides. Of the earthly oxides the most generally used is alumina either in common state of alum or in triacetate of alum [12]. There are three ways of applying a mordant to a fabric and these are, postmordanting, simultaneous mordanting and premordanting. The choice of which mordanting process to use depends on the nature of the natural dye, nature of fibre to be dyed, type of mordant to be used and quantity and quality of hue required (Gupta et al.2001). In premordanting there is pre-treatment of the fabric with other chemical assistants and in postmordanting of the fabric compounds like chitosan and other metal salts are used to help in improving the fastness of the dye. It should be noted that it is very possible to dye without a mordant for example natural dye from indigo plant does not need mordanting but the use of a mordant usually results in a better, brighter and a more permanent colour.

\section{Methodology}

\section{Extraction of the dye}

The process of extraction of the colour component from source natural dye material is an important step for dyeing any textile substrate to maximize the colour yield. According to [19] standardization of the extraction process and improving extraction variables result in better colour yield and reduced extraction and dyeing costs. In this work the plant bark was used for the three tree plants used and these were sourced from Chivi district in Masvingo province in Zimbabwe. The bark was allowed to dry within a period of a week, avoiding direct sunlight as this could have an effect on the dye structure. After drying the barks it was then ground into a fine powder using a pestle and mortar as means to facilitate the extraction process by increasing surface area of the source material. The dye was extracted using the cold extraction under gravity method. The dye was separated from the solvent using a rotary extractor which evaporates the solvent under vacuum and then allowed to dry for a period of three hours.

\section{Pretreatment of the fabric}

Table 2: Pretreatment of fabric.

\begin{tabular}{|c|c|c|c|c|}
\hline & A1 & A2 & A3 & A4 \\
\hline $\begin{array}{c}\text { Mordant } \\
\text { weight }\end{array}$ & $0.5 \mathrm{~g}$ & $1.0 \mathrm{~g}$ & $1.5 \mathrm{~g}$ & $2.0 \mathrm{~g}$ \\
\hline M: L ratio & $1: 50$ & $1: 50$ & $1: 50$ & $1: 50$ \\
\hline
\end{tabular}

Pre-bleached $100 \%$ cotton fabric pieces were put in a beaker and brought to boil whilst stirring. This process of premordanting was carried out for a period of 60 minutes at boil and the fabrics pieces were allowed to cool and soak overnight. The amount of mordant was varied from beaker A1 to A4 as shown in Table 2. The fabrics pieces were then washed with warm water after the pre-mordanting process before they were taken for dyeing.

\section{Dyeing process}

Three different methods were employed for the dyeing process in an effort to achieve different results. The dyeing was carried in the temperature range $70 \mathrm{oC}-800 \mathrm{C}$ and maintained in that range, as high temperatures might destroy dye structure.

a. Pre-mordanting: The pre-mordanted fabrics were dyed using the three different dyes extracted from the three plants. Four beakers labeled A1-A4 were used for the dyeing process for each dyestuff extracted from the plants. Predissolved extracted dyestuff was added into each beaker and the mount was $5 \mathrm{ml}(0.5 \%$ owf $)$. The fabrics pieces were then added to the dye bath and heated to reach boiling point for 15 minutes before simmering at a dyeing temperature in the range of $70^{\circ} \mathrm{C}-80^{\circ} \mathrm{C}$ for 45 minutes after which the fabric is washed using soap and allowed to dry.

b. Dye concentration-In an effort to expand the colour gamut the dyeing process was repeated using the same amount of mordant. The amount of dye used was $1 \%$ owf, $1.5 \%$ owf and $2.0 \%$ owf 
c. Non mordanted-This dyeing process was done as a control and to realise the effect of the mordant on the dyed material. The liquor ratio was maintained the same, only that the fabrics were not pretreated they were simply washed with warm tap water and dyed at the same concentration as those pretreated.

\section{Results}

\section{Extracted dye}

Table 3: Natural dye extracted.c

\begin{tabular}{|c|c|c|c|}
\hline Natural dye source & $\begin{array}{c}\text { Mass of } \\
\text { natural dye } \\
\text { extracted/g }\end{array}$ & $\begin{array}{c}\text { Mass of plant } \\
\text { material } \\
\text { used/g }\end{array}$ & $\begin{array}{c}\text { \% yield on } \\
\text { extraction }\end{array}$ \\
\hline Vitax Payos-VP & 18.448 & 150 & 12.3 \\
\hline $\begin{array}{c}\text { Pterocarpus } \\
\text { Anglonesis- PA }\end{array}$ & 26.176 & 130 & 20.1 \\
\hline $\begin{array}{c}\text { Parinari } \\
\text { Curatellifolia-PC }\end{array}$ & 33.232 & 150 & 22.2 \\
\hline
\end{tabular}

Amongst the three sources of the dyes the Vitax Payos (VP) extract had the lowest percentage yield as shown in Table 3. The colour of the dye in solution is yellow but when left to stand for a few hours it turns into a muddy brown colour. The vitax payos dye does not completely dissolve in water and thus should be applied with an additive in the dye bath. But for the sake of uniformity the dye bath additives were not used so as so as to control the results for all the three dyes extracted. The other two dye extracts namely from Pterocarpus Anglonesis (PA) and Parinari Curatellifolia (PC) showed similar colours on observation as they exhibited a reddish colour.

\section{Spectroscopy}

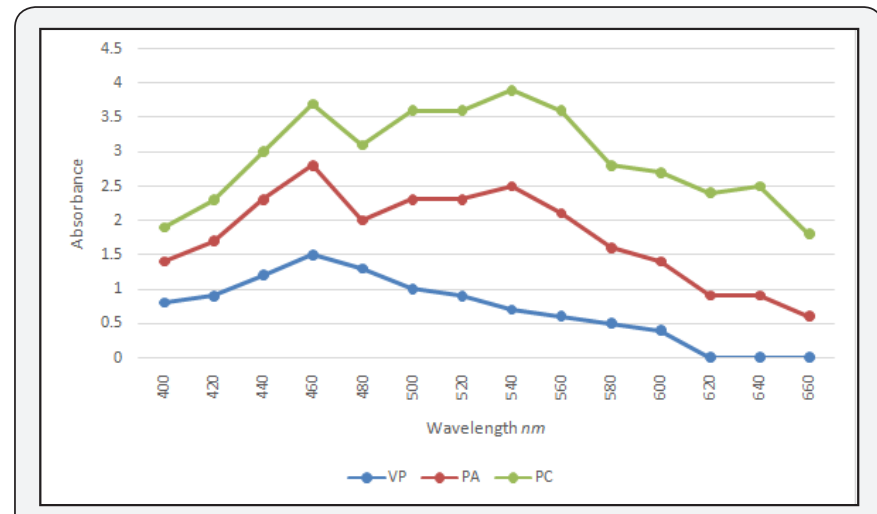

Figure 1: Absorbance of Natural dyes.

The results in Figure 1 show that the three dyes extracted for the natural plants absorb at different peaks as shown by their absorption spectral lines. The observed colour do not tell us much about the chemical structure and wavelength of maximum absorption of the dye. The two dyes PC and PA are similar in colour on observation but their absorption spectral lines are different meaning to say that they have different colouring components. PA has a maximum absorption in the range of
$540 \mathrm{~nm}$ to $640 \mathrm{~nm}$ suggesting the presence of colour red whilst VP has a peak absorbance at $460 \mathrm{~nm}$ a range in the brown shades.

\section{Dyeing results}

a. Parinari curatellifolia: The fabric readily picks up a reddish colour as soon as it is immersed in the dyebath but later turn turns to a greenish colour and then a precipitate when iron chloride (FeCI3) is used to pre-treat the fabric. This shows the presence of $\mathrm{Fe} 3+$ ions as the fabric starts to turn to a brown colour. Continuously increasing the mordant quantity also affects the colour, especially with FeCI3 as the colour becomes a dark brown. Aluminium chloride (AlCl3) showed little variation even when the mordant used was increased though the colours turned to the pink range. On the fabric piece dyed without a mordant the dye easily bleeds on washing with soap. The colour chart of the dye is shown in Figure 2 .

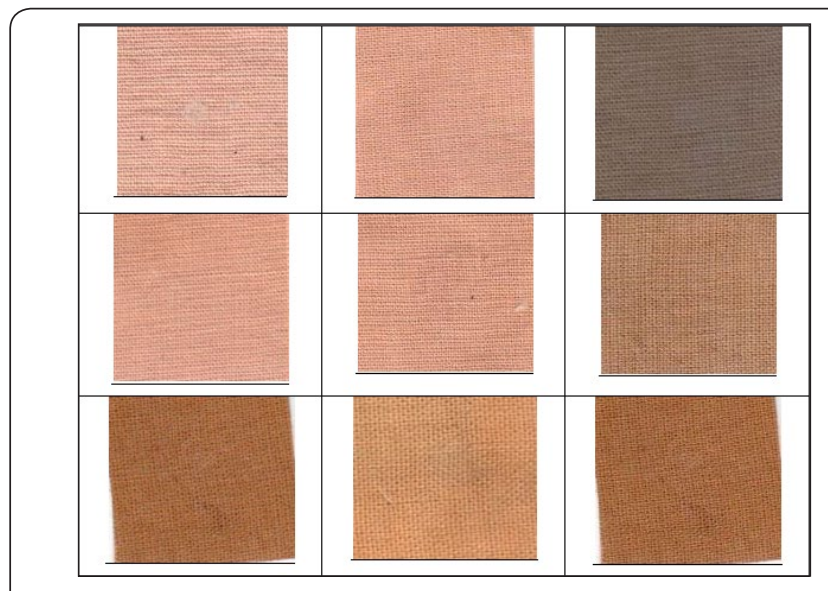

Figure 2: Colour chart for parinari curatellifolia (mobola plum).

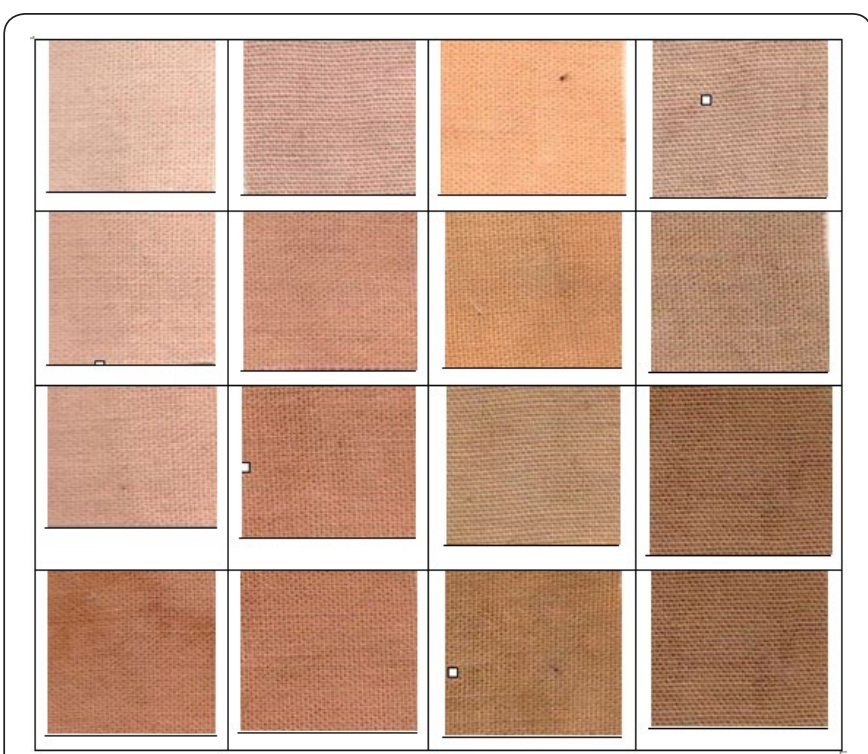

Figure 3: Colour chart of Pterocarpus anglonesis (Mukwa).

b. Pterocarpus anglonesis: The dye readily dissolves in water thereby it is readily picked up by the fabric strip as 
soon as it is immersed in the dyebath. This dye produced the highest number of shades depending with the mordant used refer to the colour chart Figure 3. Using potassium dichromate (K2Cr207) at higher concentrations resulted in more reddish shades. Aluminium chloride ( $\mathrm{AlCl} 3$ ) produced the lighter shades similar to when the fabric is dyed without the mordant.

c. Vitax payos- On adding the fabric in the dye bath, it slowly picks up a brownish colour and when left to stand a greenish precipitate is formed. The shades obtained from the dyed samples were not level when the mordant iron chloride was used. The colour chart for this dye was not as wide as compared to those of the other two dyes extracted. Using aluminium chloride (AICI3) and potassium dichromate (K2Cr207) did not produce any noticeable result though high concentration of dye and high concentration of mordant were both tried. Iron chloride produced slightly different results when the quantity used to pre-treat the fabric was altered but the shades were not very different as shown in colour chart Figure 4.

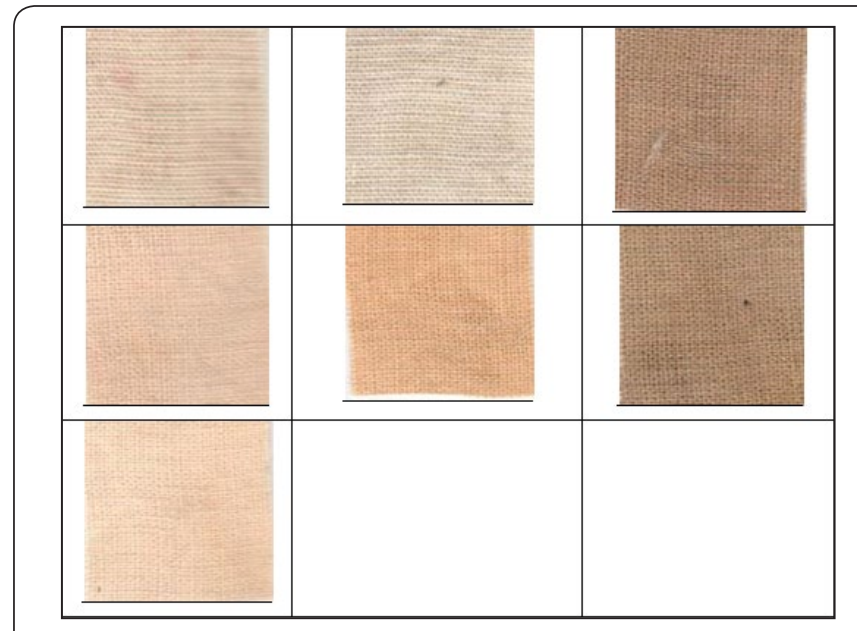

Figure 4 : Colour chart for Vitax payos.

\section{Discussion}

\section{Shade expansion}

Pterocarpus anglonesis (Mukwa) natural dye showed that a higher number of shades are obtainable when the dyeing parameters like mordant quantity, mordant method used, dyeing time and concentration of dye used were varied. To expand the colour shades obtained from natural dyes more intense primary colours can be used, for example red, blue and green or yellow are used. The more intense colours may not be in abundance locally but plants that can give a closer shade can be found. Indigo dye yielding in plants can also be cultivated thereby giving us the more intense blue colour. The major advantage is using indigo is that it does not require any mordant for its application. Expanding the colour shade will help the application of natural dyes in other non textile industries like food, drugs and cosmetics. The colours shown ion the colour charts exhibit the fact that applying slight variations on natural dyes one can achieve a range of colours even at the smallest scale.

\section{Extraction methods}

At a low scale the extraction of natural dyes is done through boiling of the plant material so that the dye can be obtained. This method has problems in that some of the dye may not be extracted and also the higher temperatures used may be too harsh for the dye resulting in dye structure being destroyed [18]. Ultrasonic energy is now being used to extract the natural dyes as it saves on time and chemicals and does not affect the dye structure but its major hindrance is on the costs attached to this method of extraction [20]. The difference in method of extraction also affects the shade achieved from each natural dye. The shade also is affected by the plant characteristics and the climatic conditions under which it grows.

\section{Auxiliaries to dye bath}

When the dye from vitax payos was used there was poor levelness of shade. The problem could have been reduced or totally eliminated by addition of sodium chloride or sodium sulphate. These are inorganic salts which act as leveling agents by retarding the rate dyeing and giving a more even shade. The $\mathrm{pH}$ of the dyebath also needs to be carefully controlled by adding sodium carbonate or soda ash. All these auxiliaries help in determining the shade. Natural dyes differ in their percentages of chemicals especially tannins which can also act as mordants, therefore $\mathrm{pH}$ needs to be consistently monitored, so that all the dyeing are carried under the same levels of $\mathrm{pH}$.

\section{Mordanting process}

For the colour charts obtained from the three (3) natural dyes, only one method of mordanting was used, that is premordanting method [21]. Since there other methods through which the mordant can be introduced to the textile fibre to aid take up of the dye, they also result in different shades. Only three mordants where used to expand the colour charts with iron chloride and potassium dichromate giving marked results. The presence of $\mathrm{Fe} 3+$ and $\mathrm{Cr} 3+$ cations show different shades for the same dye used as premordanting agents. The cations in these mordants also have an effect on the shades which can be obtained. It should also be noted that iron can be used as an after dye application as it helps to warm the colours as shown when it was applied to the other samples.

\section{Conclusion}

The work has highlighted that it is possible to produce wider ranges of shades for any particular dye by varying the dyeing parameters. Despite the limitations of natural dyes one may say that the future may be extremely bright if one takes into account several strategies to go natural. These natural dyes have a place in today's world if they are processed and marketed in the best way to enlighten the users about benefits of using these dyes. Research work to find other natural plants which give the 
highest yield per given colour is also very important especially locally in Zimbabwe where there is a wider variety of species in abundance. Natural dyes cannot be thought of as substitute for synthetic dyes but they can create a market of their own that can turn out to be highly commercial. Imparting correct knowledge to the users and the market of these dyes is a stepping stone in the process of finding a correct synergy between extraction and the use of the dyes. Some cultivation techniques for certain staple vegetation colouring matter must be researched in order to achieve an acceptable gamut and fastness properties. Natural dye sources are not only limited to plants but other natural sources like insects. This development of a wider range of colours can be of great benefit to the communities where the villagers survive on small handicraft work as this will add more aesthetic value to their wares.

\section{References}

1. Glowacki ED, Voss G, Leonat L, Irimia-Vladu M, Bauer S, et al. (2012) Indigo and Tyrian Purple-From Ancient Natural Dyes to Modern Organic Semiconductors. Israel Journal of Chemistry 52(6): 540-551.

2. Gilbert KG, Cooke DT (2001) Dyes from plants: Past usage, present understanding and potential. Plant Growth Regulation 34(1): 57-69.

3. Duff DG, Sinclair RS (1989) Laboratory Course in Dyeing, (4 $4^{\text {th }}$ edn), Bradford Society of Dyers and Colourists.

4. Duran N, Teixeira MF, De Conti R, Esposito E (2002) Ecological-friendly pigments from fungi. Crit Rev Food Sci Nutr 42(1): 53-66.

5. Gupta D, Kumari S, Gulrajani M (2001) Dyeing studies with hydroxyanthraquinones extracted from Indian madder. Part 2: Dyeing of nylon and polyester with nordamncanthal. Coloration Technology 117(6): 333-336.

6. Tiwari V, Vankar PS (2001) Unconventional natural dyeing using microwave and sonicator with alkanet root bark. Colourage 48(5): 2528.

7. Sivakumar V, Vijaeeswarri J, Anna JL (2011) Effective natural dye extraction from different plant materials using ultrasound. Industrial Crops and Products 33(1): 116-122.
8. Azeredo HMC (2008) Betalains: properties, sources, applications, and stability-a review. International Journal of Food Science and Technology 44(12): 2365-2376.

9. Borges ME, Tejera RL, Díaz L, Esparza P, Ibáñez E (2012) Natural dyes extraction from cochineal (Dactylopius coccus). New extraction methods. Food Chemistry 132(4): 1855-1860.

10. Veeman M, Cocks M, Muwonge A, Choge S, Campbell B (2001) Markets for Three Bark Products in Zimbabwe: A Case Study of Markets for Bark of Adansonia digitata, Berchemia discolor and Warburgia salutaris, Institute of Environmental Studies, University of Zimbabwe, Harare, Zimbabwe, IES 18: 52-70.

11. Cavendish W (2000) Empirical Regularities in the Poverty-Environment Relationship of Rural Households: Evidence from Zimbabwe. World Development 28(11): 1979-2003.

12. Braedt O, Standa-Gurida W (2000) Woodcraft markets in Zimbabwe. International Tree Crops Journal 10(4): 367-384.

13. Bhattacharya SD, Shah AK (2000) Metal ion effect on dyeing of wool fabrics with catechu. Journal of the Society of Dyers and Colorists 116(1): 10-12.

14. Gulrajani ML (2001) Present status of natural dyes. Indian Journal of Fibre \& Textile Research 26: 191-201

15. Vankar p (2016) Handbook on natural dyes for industrial applications (extraction of dyestuff from flowers, leaves, vegetables). ( $2^{\text {nd }}$ edn), NIIR project consultancy services, Delhi, India 30-45.

16. Wild H, Biegel H (1972) A Rhodesian botanical dictionary of African and English plant names. ( $1^{\text {st }}$ edn), Salisbury.

17. Gulrajani ML, Gupta D (1992) Introduction to Natural Dyes. Indian Institute of Technology, Delhi.

18. NIIR (National Institute of Industrial Research-India) (2006) The Complete Book on Natural dyes \& pigments. ( $1^{\text {st }}$ edn), Asia Pacific Business Press, New Dehli, India.

19. Samanta AK, Konar, A (2011) Dyeing of textiles with natural dyes. INTECH Open Access Publisher, UK.

20. Merdan NS, Eyupoglu, NM Duman (2016) "Ecological and Sustainable Natural Dyes". In Textiles And Clothing Sustainability: Sustainable Textile Chemical Processes ( $1^{\text {st }}$ edn), 1-43.

\section{Your next submission with Juniper Publishers} will reach you the below assets

- Quality Editorial service

- Swift Peer Review

- Reprints availability

- E-prints Service

- Manuscript Podcast for convenient understanding

- Global attainment for your research

- Manuscript accessibility in different formats

( Pdf, E-pub, Full Text, Audio)

- Unceasing customer service

Track the below URL for one-step submission https://juniperpublishers.com/online-submission.php 